\title{
Thermomechanical Analysis of a Compact-Design High Heat Load Crotch Absorber*
}

\author{
I. C. Sheng, S. Sharma, R. Rotela and J. Howell \\ Advanced Photon Source, Argonne National Laboratory \\ 9700 South Cass Avenue, Argonne, Illinois 60439
}

\section{Abstract}

The Advanced Photon Source (APS) is a third-generation synchrotron facility built to generate extremely powerful $x$ rays. $x$-ray absorbers in the APS dipole vacuum chambers, known as crotch absorbers, are subjected to a very high power density of $750 \mathrm{Watt} / \mathrm{mm}^{2}$ at $300 \mathrm{~mA}$ of beam current. In the compact design of the APS crotch absorbers, this high heat load is handled by a combination of optimized geometry, fins for power dispersion and cooling efficiency, and a material with high fatigue strength (Glidcop). The basic design and the results of detailed thermomechanical finite element analysis are presented in this paper.

\section{INTRODUCTION}

Each of the bending magnets of the APS storage ring emits a horizontal $x$-ray fan of $78.5 \mathrm{mrads}$ with a power density of $750 \mathrm{Watt} / \mathrm{mm}^{2}$ at $300 \mathrm{~mA}$. Only $1.8 \mathrm{mrad}$ of this fan is extracted to the beamline. The remaining fan is intercepted by a string of water-cooled absorbers in order to protect the vacuum components. A crotch absorber located at the downstream end of the dipole vacuum chamber intercepts most of these $\mathrm{x}$-rays. With a source distance of approximately $1.8 \mathrm{~m}$, the vertical $\mathrm{x}$-ray beam size at the crotch absorber is $0.2 \mathrm{~mm}$ at normal incidence. This results in a vertically-integrated linear power density of $145 \mathrm{w} / \mathrm{mm}$, which is too high for the conventional water-cooled copper absorbers. One approach to deal with this extreme power density is to use a beryllium diffuser brazed to the copper absorber [1]. The beryllium diffuses the $x$-ray power by absorbing softer $x$-rays through its thickness, thus spreading the heat load over a larger volume. The earlier APS crotch absorber designs $[2,3]$ were based on this concept. In addition, Glidcop [4] was used for the absorber body instead of OFHC copper, because Glidcop has high fatigue strength at elevated temperatures. However, these designs were found to be difficult to implement in production because of unreliable braze joints between beryllium and Glidcop. In the present design, which has been used successfully for the fabrication of all crotch absorbers, the use of beryllium as a diffuser has been eliminated.

\section{BASIC DESIGN}

The present crotch absorber (see Figure 1) has two distinct features: a central nose region, and two side wings. Each of the side wings, as well as the nose, intercepts approximately 4 kilowatts of beam power. The side wings are inclined to the incident beam by approximately 20 degrees. This reduces the linear power density and the resulting temperature rise in the

*Work supported by U.S. DOE Office of Basic Energy Sciences under Contract No. W-31-109-ENG-38. wings by 66 percent. The absorber's nose is inclined vertically by 11 degrees, which spreads the beam power vertically. However, since the initial beam size at normal incidence is very small ( $0.2 \mathrm{~mm}$ vertically), the advantage of vertical inclination is not significant. At $300 \mathrm{~mA}$, the temperature rise in the nose region would be $350^{\circ} \mathrm{C}$ which is unacceptable for Glidcop under thermal cycles
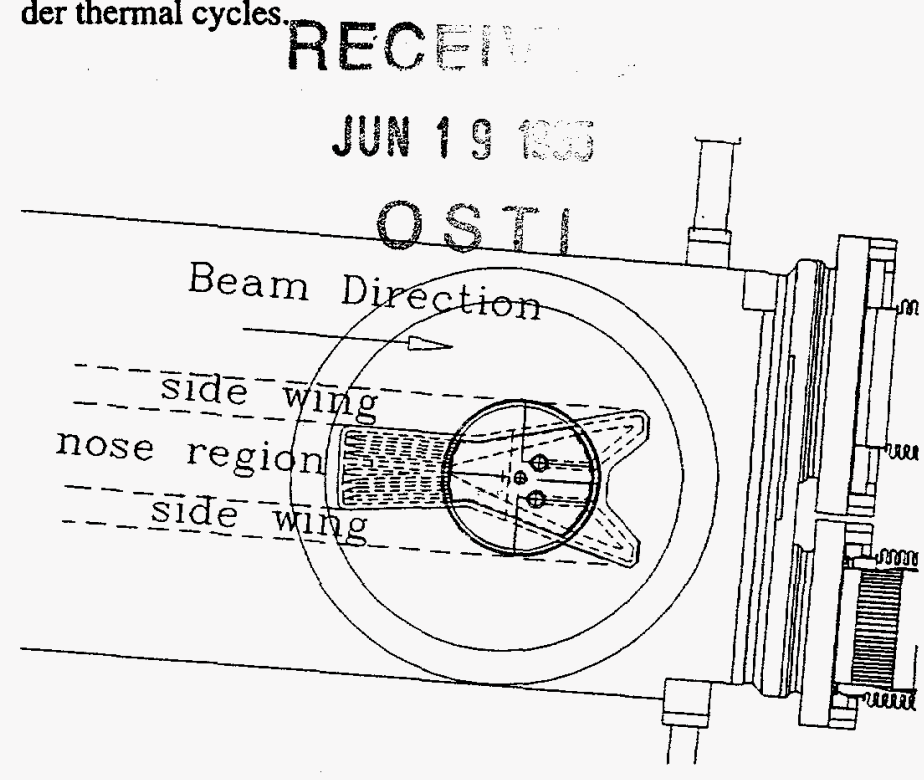

Figure 1. Plane View of the Crotch Absorber

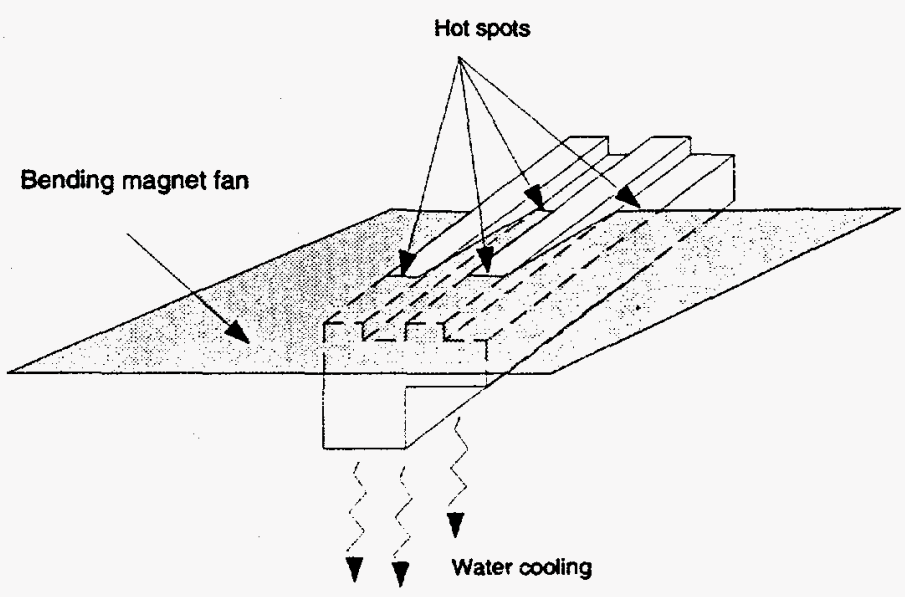

Figure 2. Bending Magnet Fan Intercepted by the External Fins

A new approach is used to spread the beam power more effectively in the nose region. In this approach, illustrated in Figure 2, vertical fins are machined on the Glidcop surface, which split the beam footprint into two parts. The first part is intercepted by the fins, whereas the second part is intercepted by the grooves between the fins. At the 11-degree angle of in-

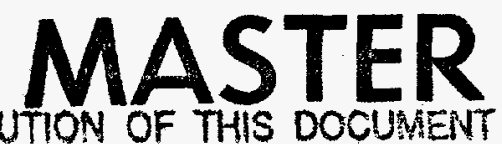

The submitted manuseript has been authored by a contractor of the U.S. Government under contract No. W-31-109ENG-38. Accordingly, the U.S. Government retains a nonexclusive, royalty-free license to publish or reproduce the published form of this contribution, or allow others to do so, for U. S. Government ourposes. 


\section{DISCLAIMER}

Portions of this document may be illegible in electronic image products. Images are produced from the best available original document. 
cidence, the separation between the two beam intercepts is 8 $\mathrm{mm}$. Since the water channels are only about $5 \mathrm{~mm}$ away from the surface, this separation reduces the surface temperature rise considerably (see below). The beam power can be distributed even more effectively by using $V$-shaped fins. However, for the present beam power, the $V$-shaped fins are not needed and are not used in order to reduce the machining cost.

Internal fins are also used inside the water channels of the absorber to enhance the heat transfer. The water channels and the internal fins are made by EDM (electric discharge machining) to meet an important design criterion of avoiding waterto-vacuum joints. The Glidcop body is brazed to an OFHC copper plug, which directs the water flow, and a stainless steel cylinder, by which the absorber is attached to a Conflat flange. All brazing is done in a vacuum furnace with $50-50$ goldcopper alloy. Further details on the absorber design, fabrication, and brazing are given in [5].

\section{TEMPERATURE RISE}

Finite element models were constructed to determine the temperature rise and stresses in the crotch absorber. Only the results for the nose region, where the temperature rise and stresses are highest, are presented here. For the thermal analysis only a representative strip of the absorber--consisting of two external fins, one water channel, and one internal fin--was modeled. A film coefficient of $1.5 \mathrm{Watt} /\left(\mathrm{cm}^{2}{ }^{\circ} \mathrm{C}\right)$ was used based on a 7.5 gallon/minute (GPM) water flow in the cooling channels.

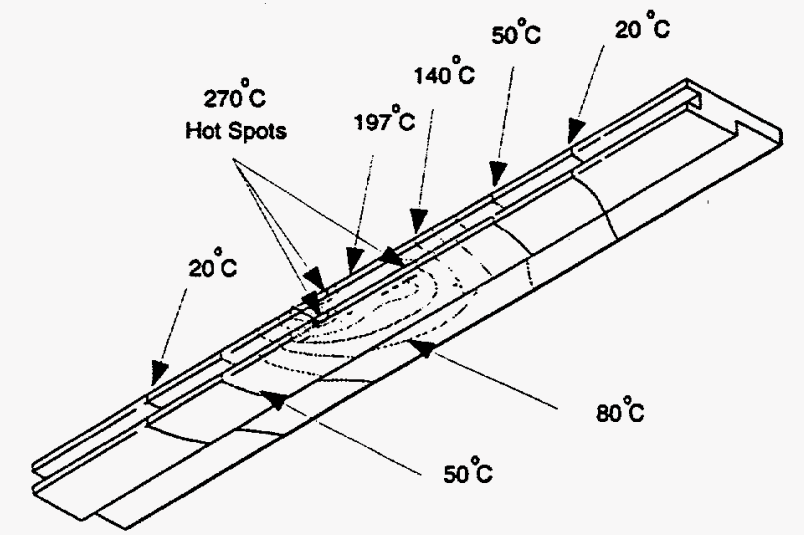

Figure 3. Temperature Rise Contour in the Nose Region

The temperature contours are shown in Figure 3. In the two spots where the beam is intercepted, the temperature rises by $270^{\circ} \mathrm{C}$. The isotherms in the figure show spreading of the beam power due to the external fins. At the cooling channels, the maximum temperature rise is approximately $135^{\circ} \mathrm{C}$, and the heat flux is $2 \mathrm{Watt} / \mathrm{mm}^{2}$, both of which are well below the critical boiling conditions. If no external and internal fins are used, then the maximum temperature rises at the fins and the cooling channels are 350 and $145^{\circ} \mathrm{C}$, respectively.

\section{STRESS}

The fins in the absorber body also help in reducing the pressure stresses from the cooling water at $150 \mathrm{psi}$. Moreover, the pressure stresses, in contrast to the thermal stresses, are compressive on the water channel side, and tensile on the incident beam side. The combined effective (von Mises) stress is therefore reduced when both the thermal and pressure loads are considered.

Due to symmetry, only one-half of the nose section was modeled. Figure 4 shows the von Mises stress contours in this 3-D model. As expected, the two spots where the beam is intercepted experience the highest stress with a magnitude of about $20 \mathrm{ksi}$. In comparison, the yield strength and tensile strength of Glidcop are $55 \mathrm{ksi}$ and $65 \mathrm{ksi}$, respectively [6].

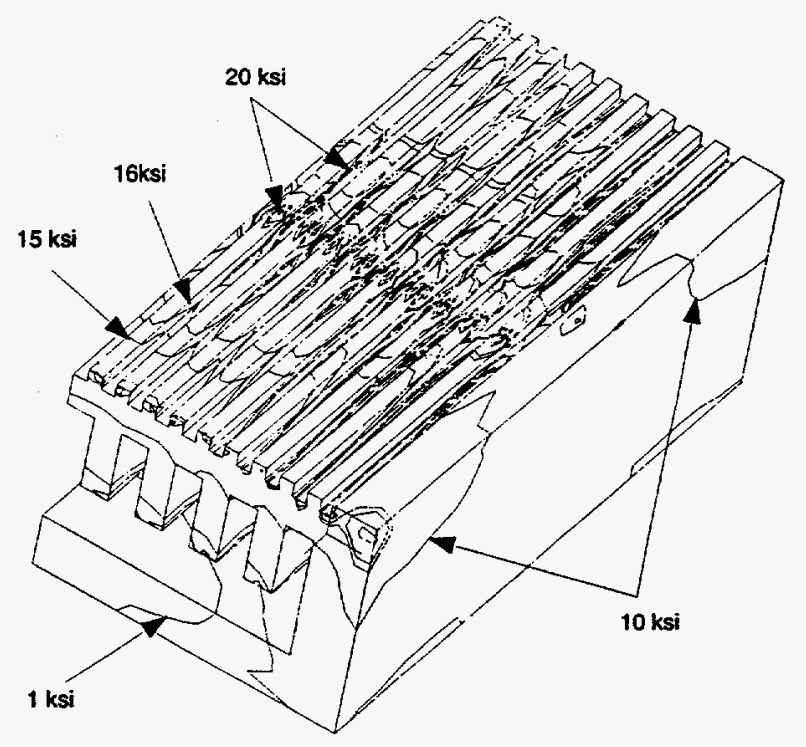

Figure 4. Stress Contour in the Nose Region

\section{CONCLUSIONS}

The basic design features of the APS crotch absorber have been described, and analysis results have been presented to show the effect of external and internal fins in reducing the temperature rise and stresses in the absorber. The compact design, which does not use beryllium as an $\mathrm{x}$-ray diffuser, has been shown to safely handle $300 \mathrm{~mA}$ of beam current.

\section{ACKNOWLEDGMENTS}

The authors would like to thank Ms. Catherine Eyberger for editing this paper.

\section{REFERENCES}

[1] D. M. Mills, D. H. Bilderback, and B. W. Baterman, "Thermal Design of Synchrotron Radiation Exit Port at CESR," IEEE Transactions on Nuclear Science, NS-26, 3854-3856, June 1979.

[2] I. C. Sheng and J. Howell, "Thermal Analysis of the Crotch 
Absorber in APS," Proc. of SPIE--The International Society for Optical Engineering, High Heat Flux Engineering, Ali M. Khounsary, Editor, 1739, 200-213, 1992.

[3] I. C. Sheng, S. Sharma, E. Rotela and J. Howell, "A Conceptual Design and Thermal Analysis of High Heat Load Crotch Absorber," Proc. of the 1993 Particle Accelerator Conference, 2, 1497-1499. 1993.

[4] "Glidcop Grade AL-15 Dispersion Strengthed Copper," Technical Data, SCM Metal Products, Inc., 1988.

[5] S. Sharma, E. Rotela, I. C. Sheng and J. Howell, unpublished paper.

[6] J. B. Conway, R. H. Stentz and H. T. Berling, "High Temperature, Low-Cycle Fatigue of Advanced Copper-Base Alloys for Rocket Nozzles; Part II -NASA1.1, Glidcop, and Sputtered Copper Alloys," NASA-Lewis Research Center, N-75-11076, 1974.

\section{DISCLAIMER}

This report was prepared as an account of work sponsored by an agency of the United States Government. Neither the United States Government nor any agency thereof, nor any of their employees, makes any warranty, express or implied, or assumes any legal liability or responsibility for the accuracy, completeness, or usefulness of any information, apparatus, product, or process disclosed, or represents that its use would not infringe privately owned rights. Reference herein to any specific commercial product, process, or service by trade name, trademark, manufacturer, or otherwise does not necessarily constitute or imply its endorsement, recommendation, or favoring by the United States Government or any agency thereof. The views and opinions of authors expressed herein do not necessarily state or reflect those of the United States Government or any agency thereof. 